\title{
Combustion Analysis and Operation Adjustment of Thermal Power Unit
}

\author{
Li Jun \\ Grid Technology Center \\ State Grid Shandong Electric Power Research Institute \\ Jinan, China \\ lijun_sdu@hotmail.com
}

\author{
Li Weiwei \\ Network Center \\ Shandong University of Arts \\ Jinan, China \\ liweiwei@sdca.edu.cn
}

\begin{abstract}
The characteristics of main low nitrogen combustion technologies are to be introduced. By analysis of unit's typical outfire accident after low nitrogen combustion transformation, proposed some targeted solutions to optimize operation of the thermal power unit, such as adjustment of the air distribution, optimization of the oxygen control and reasonable blending combustion etc., can effectively ensure the combustion stability and reduce the concentration of nitrogen oxides emissions, provide a reference for similar units.
\end{abstract}

Keywords-low nitrogen combustion; staging combustion; blending combustion; coal-air ratio; thermal power unit

\section{INTRODUCTION}

With the rapid development of social economy, the power energy consumption is more and more big, the air pollution emissions is consequent increasing. As the most important part of Chinese electricity, thermal power generate nitrogen oxide pollutants during combustion of fuels, the generation of nitrogen oxides is part of the combustion reaction $[1,2]$. The main combustion nitrogen oxides $\mathrm{NO}$ and $\mathrm{NO}_{2}$, collectively referred to as NOx. NOx in the atmosphere dissolved in the water will be generated as nitric acid rain. Acid rain caused extensive damage on the environment, causing huge economic losses[3]. To effectively control emissions from thermal power units of atmospheric pollutants, Emission standard of air pollutants for thermal power plants of China implemented since 2012 provides a thermal power plant air pollutant emission concentration limits, surveillance and monitoring requirements. Standard noted that after the transformation of thermal power to control the concentration of nitrogen oxide emissions within the $100 \mathrm{mg} / \mathrm{m}^{3}$.

In order to achieve clean combustion, reducing the NO of emission pollution, technical measures can be divided into two categories, one is the furnace denitrification, the other is the De-NOx[4]. Furnace nitrogen combustion technology is the use of various means to control NOx formation during combustion, also known as low NOx combustion technology. De-NOx is also known as flue gas purification technology. The nitrogen oxides have been generated in the flue gas are reduced or absorbed, thereby reducing NOx emissions. Compared to De-NOx, low NOx combustion has a wide range of applications, simple structure and cost-effective advantages[5]. It is the most important and relatively mature measure to reduce coalfired boiler NOx emissions. In general, these measures can reach up to $50 \%$ of the removal rate. Thus, thermal power units generally adopt low NOx combustion transformation.

\section{Characteristics OF LOW NitrogeN COMBUSTION TECHNOLOGY}

Furnace denitrification can be divided into various types according to different combustion technology, among them, the efficiency of fuel staging combustion is higher, it is effective measures to reduce NOx emissions[6, 7], NOx emissions from coal-fired boilers can be reduced more than $50 \%$. Staging combustion includes the following technical characteristics.

\section{A. Distribution of three vertical spaces}

In about 3 meters away from main burner area at the top of the above, 3-4 layers separate over fire air (SOFA) to be set up, it accounts for about $25 \%$ of the total air volume. First, it ensures the reduction height between the main burners and overfire air (OFA) high enough to reduce the fuel type and heat type NOx. At the same time, all the OFA vents are designed to swing up and down spout to achieve on-demand targeting air and adjust the boiler outlet smoke temperature deviation.

The primary combustion zone is divided into higher and lower concentration combustion space, for example, one $300 \mathrm{MW}$ boiler with five layers of pulverized coal burner, in its main combustion zone, to build the lower concentration of pulverized coal burner consists of four main combustion zone has a high ignition steady combustion characteristics the lower part, to ensure accounting for about $80 \%$ of the pulverized coal boiler overall centralized arrangement favorable to the fire burn, the runtime can be appropriate to reduce the excess air ratio in this region by adjusting the furnace temperature reached a high level in this area, in the state of hypoxia lower, NOx reduction was large amount of deposits, into the upper primary combustion zone, reducing the generated NOx, runtime excess air coefficient in this region is about 1.0, to ensure the boiler furnace main combustion zone a sufficiently high temperature level. So, the fuel staging combustion technology for reducing fuel NOx formation and thermal NOx formation have extremely significant results[8].

\section{B. Two areas distribution of the combustion zone}

As can be seen from Fig.1, in the main combustion zone, we form a distinct characteristic of the central area 
on the combustion space and near-wall region distribution in the horizontal section of the furnace through the design and transformation[9,10]. It is conducive to the main burner in the furnace area to organize a high concentration of pulverized coal, high-temperature, low oxygen combustion core area. Meanwhile, at a lower excess air ratio, fuel type NOx generation can be effectively suppressed, the combustion temperature can be suppressed low temperature type NOx generated fundamentally, to achieve the goal of low NOx combustion furnace.

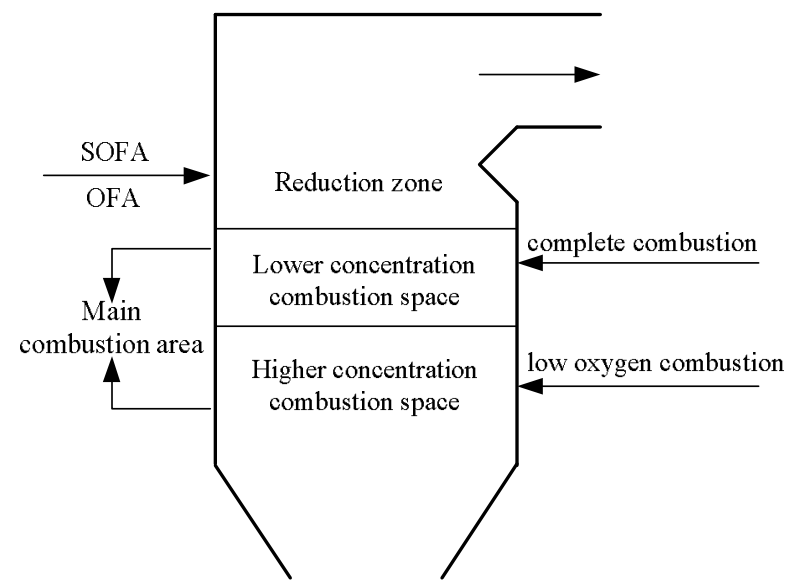

Figure 1. Schematic diagram of staging combustion.

Using air staging combustion technology is not only an important means of reducing NOx emissions and improve the rate of burn pulverized coal, while using horizontal SOFA swing adjustment, but also help reduce the furnace exit side flue gas temperature deviation caused superheater and reheaters wall temperature excursion.

\section{ACCIDENT ANALYSIS AND SUMMARY}

Taking a typical 300MW unit as an example, analyzes the burning accident case after its low nitrogen combustion transformation. The unit uses the design and manufacture of Shanghai Boiler Works SG 1025/17.47-M878 type subcritical, single drum, single reheat, control loops, solid pulverized coal furnace slag, $\Pi$ type open layout, designed for lean coal. Boiler adopt double inlet and outlet ball straight grinding powder system, tangentially fired and swing pulverized coal nozzle.

\section{A. Accident process overview}

One day 8:16, No.4 unit's load was 220MW, the main steam pressure was $16.9 \mathrm{MPa}$, the main steam temperature was $536^{\circ} \mathrm{C}$, the main steam flow rate was $700 \mathrm{t} / \mathrm{h}$. Induced draft fan, forced draft fan, primary air fan, booster fan were operating in the auto mode. $4 \mathrm{~A}$ and $4 \mathrm{~B}$ two sets milling system were operating, the indicators and parameters were normal, no repair work. No.4 unit's short soot blowers were blowing. 8:16:25, the operator found that the furnace pressure fluctuations, $\max$ to $+320 \mathrm{~Pa}$, and then rapidly decreased to $-2658 \mathrm{~Pa}$, reached master fuel trip (MFT) action value $(-2490 \mathrm{~Pa})$. The boiler flame-lass protection acted and the first reason was furnace pressure low. On-site inspection, there are a large number of slag in slag salvaging machine.

\section{B. Accident process analysis}

Check out the action of fire detection, from 8:16:31 to $8: 16: 36$, there have been 12 fire detection signal sent no fire. According to the order, 8:16:31 was A1 layer \#3 corner. 8:16:33 was A1 layer \#4 corners. 8:16:35 were A1 layer \#1 corner, A2 layer \#1, 4 corner, B1 layer \#1 corner, B2 layer \#1, 4 corner, it seized a total of seven fire. 8:16:36 were B1 layer \#3, 4 corners, B2 layer \#3 corner. Because of \#4 Unit's A1 layer (lowest layer) to participate in the whole furnace of fire detection only fire-tripping logic, fire signal of the other layers of fire detection adopt the logical 2/4. 8:16:35, A2, B1, B2 layers are met layer fire signal inspection requirements, so the boiler before 8:16:36 MFT and no fire occurred mouth resection.

In the power plant, the excess oxygen in flue gas has been measured and used to control the combustion efficiency. Oxygen value was $3.6 \%$ before the boiler outfire. This value was low to $220 \mathrm{MW}$ load. It easy to result from a lack of oxygen to the main combustion zone produced adherent reducing atmosphere, adverse to prevent boiler coking.

Before boiler MFT, the mode induced draft fan, forced draft fan and primary air fan were auto. Instruction and feedback tracking was properly. The fan current, air pressure, baffle opening were no abnormal changes, excluded the air and gas system imbalance caused by pressure abnormal changes.

When an event occurred, the transfer of heat from coal is higher $(22.38 \mathrm{MJ} / \mathrm{kg})$. A and B milling system operation, the total output was $90 \mathrm{t} / \mathrm{h}$ or so, the capacity of the wind was $156 \mathrm{t} / \mathrm{h}$. Check before low calorific value under the same load, the total output and capacity of the wind mill with the same event occurred. Part in all kinds of no new types of mixed coal blending, indexes and lean coal and anthracite was close to, but from the access part of the mix of coal, coal composition were uncertainty. The information of coal in coal yard is shown in the following Table I. The mixed coal was Luan and Yangquan in the day of accident happened.

TABLE I. THE INFORMATION OF COAL IN COAL YARD

\begin{tabular}{|c|c|c|c|c|c|c|c|}
\hline Mine Origin & Mad\% & Ad\% & Vad\% & Vdaf\% & Fcd\% & Std\% & Qnet \\
\hline Jinzhong & 7.2 & 27.54 & 11.32 & 15.66 & 60.52 & 1.01 & 22.67 \\
\hline Jiaozuo & 7.8 & 34.25 & 14.72 & 22.47 & 50.98 & 2.29 & 19.81 \\
\hline Luan & 11.6 & 20.81 & 11.71 & 14.86 & 66.85 & 0.35 & 24.68 \\
\hline Datong & 11.4 & 37.22 & 10.31 & 16.71 & 51.52 & 1.27 & 18.05 \\
\hline Yangquan & 7.4 & 27.36 & 8.06 & 11.32 & 63.61 & 1.06 & 22.71 \\
\hline Shouyang & 7.9 & 28.01 & 11.48 & 16.01 & 60.13 & 0.99 & 22.43 \\
\hline
\end{tabular}


The fired volatile was slightly before boiler flame failure, actual testing value was $10.3 \%$, in favour of anthracite coal, unfavourable to steady combustion. Testing values are shown in the following Table II.

TABLE II. TESTING VALUES BEFORE BOILER FLAME FAILURE

\begin{tabular}{|c|c|}
\hline Date & Vaf\% \\
\hline Day shift & 12.06 \\
\hline Middle shift & 11.82 \\
\hline Night shift & 10.31 \\
\hline
\end{tabular}

\section{Accident summary}

Local outfire happened in the boiler, furnace temperature level has fallen dramatically, furnace pressure was instantly reduced, and the induced draft fan output in a short period of time did not decreased. So, furnace pressure decreased quickly and reached the MFT action value. The cause of local outfire was the poor combustion stability and the coke dropping interfere together.

Because of the coal market and in order to cut the cost of fuel, the plant put into use high range anthracite coal cofiring but unburned combustible content in fly ash of the boiler increased. When the coal is the mixed coal above mentioned, coal-air ratio increase, fire vents distance extend and the flame combustion instability center shift. At the same time, unit load 220MW, flue gas oxygen content about 3.6\%, two layers SOFA opening 100\%, did not exclude the serious shortage of oxygen.

\section{DESIGN AND ANALYSIS OF EXPERIMENTS}

Related tests taken to verify the impact of coal quality, mill and oxygen for NOx emissions. The standard used in the tests is Performance Test Code for Utility Boiler. The gas samples were drawn out at the outlet of air preheater with grid method, and then entered the flue gas analyzer through a gas mixer. Some sets of data for $\mathrm{O}_{2}$ and $\mathrm{NOx}$ concentrations were obtained at each experimental condition, and all of the data were corrected based on $\mathrm{O}_{2}$ concentration $6 \%$ or the excess air ratio 1.4 according to the standard of Atmosphere Pollutants Emission Standards for Thermal Power Plants.

\section{A. Different combinations of coal and mills test}

Normally, the boilers burning coal with high volatile produce less NOx. Combustion characteristics of coal influence the boiler operation mode. The coal with high volatile can be burnt out easily, and allows a low excess air ratio which restrains the conversion of fuel nitrogen to NOx[11,12]. Combustion characteristics of coal influence the oxygen concentration in furnace significantly.

We take the experiments of different combinations of coal and mills test their effect on NOx emissions under different unit load and $\mathrm{O}_{2} \%$. As can be seen from Table III, No.1 and No.2 are full load working condition under different mills combination and same coal combination, NOx emission concentration is affected by the combination of mills. The lower mills combination can help to reduce the NOx emission concentration.

No.3, No.4 and No.5 are the variable load conditions under same mills combination. As can be seen from the results, when the unit load gradually reduced, NOx emission concentration decreased. Because of high-load operation of oxygen is low, so the lowest concentration of NOx at high loads.

TABLE III. TESTING VALUES OF DIFFERENT COMBINATIONS OF COAL AND MILLS

\begin{tabular}{|c|c|c|c|c|c|}
\hline \multirow{2}{*}{ No. } & Condition & $\begin{array}{c}\text { Unit } \\
\text { Load }\end{array}$ & $\mathbf{O}_{\mathbf{2}} \%$ & Mill & NOx \\
\cline { 2 - 6 } & - & $\boldsymbol{M} \boldsymbol{W}$ & $\boldsymbol{\%}$ & - & $\boldsymbol{m g} \boldsymbol{m}^{\mathbf{3}}$ \\
\hline 1 & Coal 1 & 284 & 3.1 & ABCE & 347 \\
\cline { 3 - 6 } & Coal 1 & 283 & 3.3 & BCDE & 393 \\
\hline 3 & Coal 1 & 285 & 3.4 & CDEF & 297 \\
\hline 4 & Coal 1 & 223 & 4.7 & CDEF & 326 \\
\hline 5 & Coal 1 & 160 & 5.1 & CDEF & 349 \\
\hline 6 & Coal 2 & 290 & 3.5 & BCDE & 281 \\
\hline 7 & Coal 2 & 165 & 4.4 & BCDE & 329 \\
\hline
\end{tabular}

No.6 and No.7 are different load working condition under same mills and same coal combination. Results show that the NOx concentration on the high load is lower than NOx concentration on low load.

\section{B. Air leakage ratio test}

By taking the air preheater leakage rate test under different operating conditions, we can conclude that the air leakage rate is higher when the oxygen higher, which is not conducive to control NOx emissions, as shown in Table IV.

TABLE IV. AIR LEAKAGE RATIO OF AIR PREHEATER UNDER DIFFERENT CONDITIONS

\begin{tabular}{|c|c|c|c|c|}
\hline \multirow{2}{*}{ No. } & Unit Load & $\mathbf{O}_{\mathbf{2}} \%$ & $\begin{array}{c}\text { A air leakage } \\
\text { ratio }\end{array}$ & $\begin{array}{c}\text { B air leakage } \\
\text { ratio }\end{array}$ \\
\cline { 2 - 5 } & $\boldsymbol{M W}$ & $\boldsymbol{\%}$ & $\boldsymbol{\%}$ & $\boldsymbol{\%}$ \\
\hline 1 & 284 & 3.1 & 11.4 & 11.5 \\
\hline 2 & 283 & 3.3 & 11.2 & 10.3 \\
\hline 3 & 285 & 3.4 & 12.3 & 11.2 \\
\hline 4 & 223 & 4.7 & 13.6 & 10.9 \\
\hline 5 & 160 & 5.1 & 14.1 & 11.1 \\
\hline 6 & 290 & 3.5 & 10.5 & 10.2 \\
\hline 7 & 165 & 4.4 & 13.9 & 12.6 \\
\hline
\end{tabular}

In the actual operation process, although sometimes the total air volume increases, but the air leakage rate increase at the same time, we need to pay attention to observe the changes of oxygen content of air preheater to ensure the stability of combustion and NOx emissions.

\section{MEASURES TAKEN}

Because of the combustion characteristics of the boiler after low nitrogen combustion transformation have a great change, therefore, the units need detailed optimization of combustion experiments to explore the best of the excess air ratio, the primary air velocity and air distribution modes.

\section{A. Adjustment of air distribution}

The air distribution is a key to the temperature distribution. Tests show that the slagging can be avoided by adjusting air distribution. By reasonably improving the 
fineness of coal particles and optimizing air distribution, combustion stability can be improved.

The horizontal swaying OFA arranged on the top of furnace and the concentric tangential combustion manner postpone mixing of air and coal powder and reduce generation of NOx. The experiment carried out at Laicheng power plant shows that NOx emission can be reduced by reducing secondary air at the bottom in furnace and increasing SOFA air at the top in furnace.

SOFA winds have a great impact on NOx. On the premise of other factors unchanged, NOx would decrease with the increase of SOFA baffle opening, the damper opening greater than $80 \%$, the NOx basic is to maintain a constant level. In addition, A and B side SOFA need to control air volume control uniform, which helps reduce NOx and unburned carbon. When combustion is extremely bad, surrounding air and SOFA can be closed.

\section{B. Optimization of oxygen control}

Excess air coefficient $\alpha$ applied to measure the combustion process in the boiler furnace whether the economy, which is defined as

$$
\alpha=\frac{21 \%}{21 \%-O_{2} \%}
$$

$\mathrm{O}_{2} \%$ is furnace flue gas oxygen content.

It is well known for industrial coal-fired boilers, the excess air coefficient $\alpha$ general control of the theoretical value of 1.3 to 1.5 , but taking into account practical considerations such as leakage and coal quality, $\alpha$ select from 1.4 to 1.8 .

With air preheater export oxygen excess air coefficient increases, NOx emission concentration increases, the outlet temperature of the furnace and the combustion temperature change is not big, irregular change appears, NOx emission concentration change is not caused by thermal NOx type change, but caused by fuel type NOx change. With the increase of excess air coefficient, oxygen burning area increases, when the nitrogen compounds in fuel combustion thermal decomposition product further oxidized to NOx provides conditions, so as to increase the fuel type of NOx. Although low oxygen operation is beneficial to control NOx emissions, but does not favor the pulverized coal burning. Checked oxygen historical data and compared with the same type of unit, the boiler combustion after low nitrogen transformation require an appropriate increase in oxygen value to increase the total amount of air, so, the optimal value of $\mathrm{O}_{2} \%$ under different unit load is shown in Fig.2.

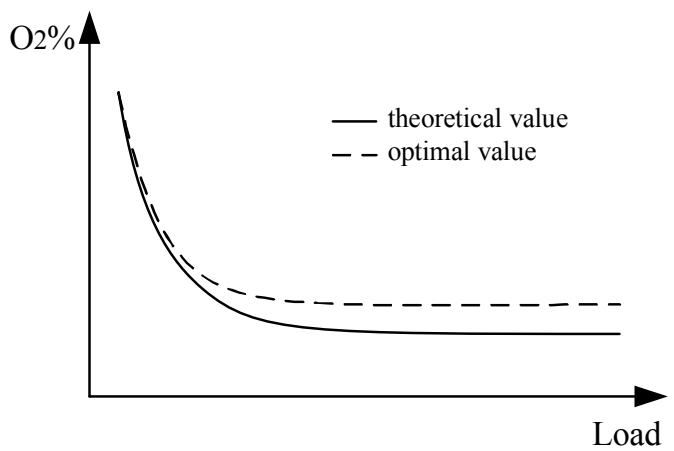

Figure 2. Optimal value of $\mathrm{O}_{2} \%$ under different unit load

\section{Reasonable blending combustion}

Combustion characteristics of mixed coal are mainly determined by the composition of the blend ratio of each single mix of coal and coal quality. Coal combustion properties very different when blended with each other is easy to form a grab burn and reduce burning effect, compared with the single coal combustion performance. Improve the purchase rate of single suitable to burn coal, as far as possible to reduce the mixed coal procurement, the incoming coal volatile according to upper limit control, reduce the anthracite incoming quantity, appropriate increase the purchase quantity optimal burning bituminous coal. The anti-interference ability of boiler combustion can be improved by controlling the coal quality.

If one power plant coal were blended, single unit as possible to maintain the same blended proportion, in order to effectively control the boiler combustion stability. Otherwise, since the amount of coal required and coal burning time is changed, the boiler control parameters need to be adjusted.

\section{CONCLUSIONS}

By adjusting the air distribution, optimizing the oxygen control, optimizing blending combustion, can effectively ensure the combustion stability and prevent the occurrence of boiler outfire due to the coke dropping occurred on the furnace, reduce the concentration of nitrogen oxides emissions and ensure environmental requirements.

\section{REFERENCES}

[1] B.Coda, F.Kluger, D.Fortsch, etc. "Coal-Nitrogen Release and NOx Evolution in Air-Staged Combustion”, Energy \& Fuels, vol. 12, pp.1322-1327, 1998.

[2] Lin Peng-yun, Luo Yong-hao, Hu Li-yuan, "Numerical simulation and analysis of the influencing factors of NOx emissions of coalfired utility boilers", Journal of Engineering for Thermal Energy and Power, vol. 22(5), pp.529-533, 2007.

[3] Kang M., Yeon T. H., Park E. D., Yie J. E.,et al. "Novel MnOx catalysts for NO reduction at low temperature with ammonia", Catalysis Letters, vol. 106(1-2), pp.77-80, 2006.

[4] M.H.Xu, J.L.T.Azevedo, M.G.Carvalho, "Modeling of the Combustion Process and NOx Emmission in a Utility Boiler", Fuel, Vol. 79(13), pp.1611-1619, 2000.

[5] Kurosea R, Makinob H, "Numerical analysis of pulverized coal cumbustion characteristics using advanced low-NOx burner", Fuel, 84, pp.693-703, 2004.

[6] D.R.Coyghanowr, Process Systems Analysis and Control, New York: McGraw-Hill, 1991.

[7] Yao Qiang, Chen chao, Technology of clean coal combustion, Beijing: Chemical Industrial Publishing Company, 2005.

[8] J.L.T Azevedo, Coimbra C.F.M and Carvalho M.G., "3-D Numerical Model for Predicting NOx Emssions From an Industrial Pulverized Coal Combustor" , Fuel, vol. 73(7) , pp.1128-1134, 1994.

[9] Hu Wei-feng, Xie Jing-mei, "Feasibility study on 600MW boiler low-NOx combustor retrofitting", Electric Power Construction, vol. 30(3), pp.70-73, 2009.

[10] Jia Hong-lu, "Flow adjustable type burners and low-NOx combustion", East China Electric Power, pp.724- 27, 1992.

[11] Fang Li-jun, Gao Zheng-yang, Yan Wei-ping, et al. "Experimental study on performance of NOx emission for low volatilization coals", Proceedings of the CSEE, 2003, 23(8): 211-214.

[12] Li Yong-hua, Li Song-geng, Feng Zhao-xing, et al. "Experimental study on the formation of NOx of brown and brown-blending coal combustion", Proceedings of the CSEE, 2001,21(8),34-36,41. 